\title{
Transportation Synchronization and Improvements for Distribution Centre and Retail Stores
}

\author{
Viraj P. Lele \\ Graduate student in Industrial Engineering at University of Houston
}

\begin{abstract}
Transportation Decision-Making" is a very important part of supply chain management. System Engineer Team at Industrial Engineering Department of Academy Sports and Outdoors, a premier sports and outdoor retailer with headquarter in Houston, has been given the project of "Transportation Synchronizations and Improvements for Distribution Center and Retail Stores" to complete. The goal of this project is to study how to synchronize and improve the transportations between its 1.5 million square-feet central distrib tion center (located at Katy, Texas) and 200 retail stores (located in 18 states of US). DMAIC technology is used to execute this project. The Team had completed the "Define" and "Measure" phase of DMAIC technology .The Team further needed help to complete the "Analyze" and "Improve" phase of this project using the material and knowledge of Supply Chain Management.
\end{abstract}

Keywords: Supply chain Management, Logistics, Transportation, Retailing, Improvements

\section{Introduction}

The DMAIC procedure is a center segment of the Six Sigma technique. It is utilized when making enhancements to a current procedure. (For making of new procedures and items, the DMADV system is taken after).
DMAIC is an acronym for the 5 key stages in a procedure change venture: Define, Measure, Analyze, Improve, and Control.

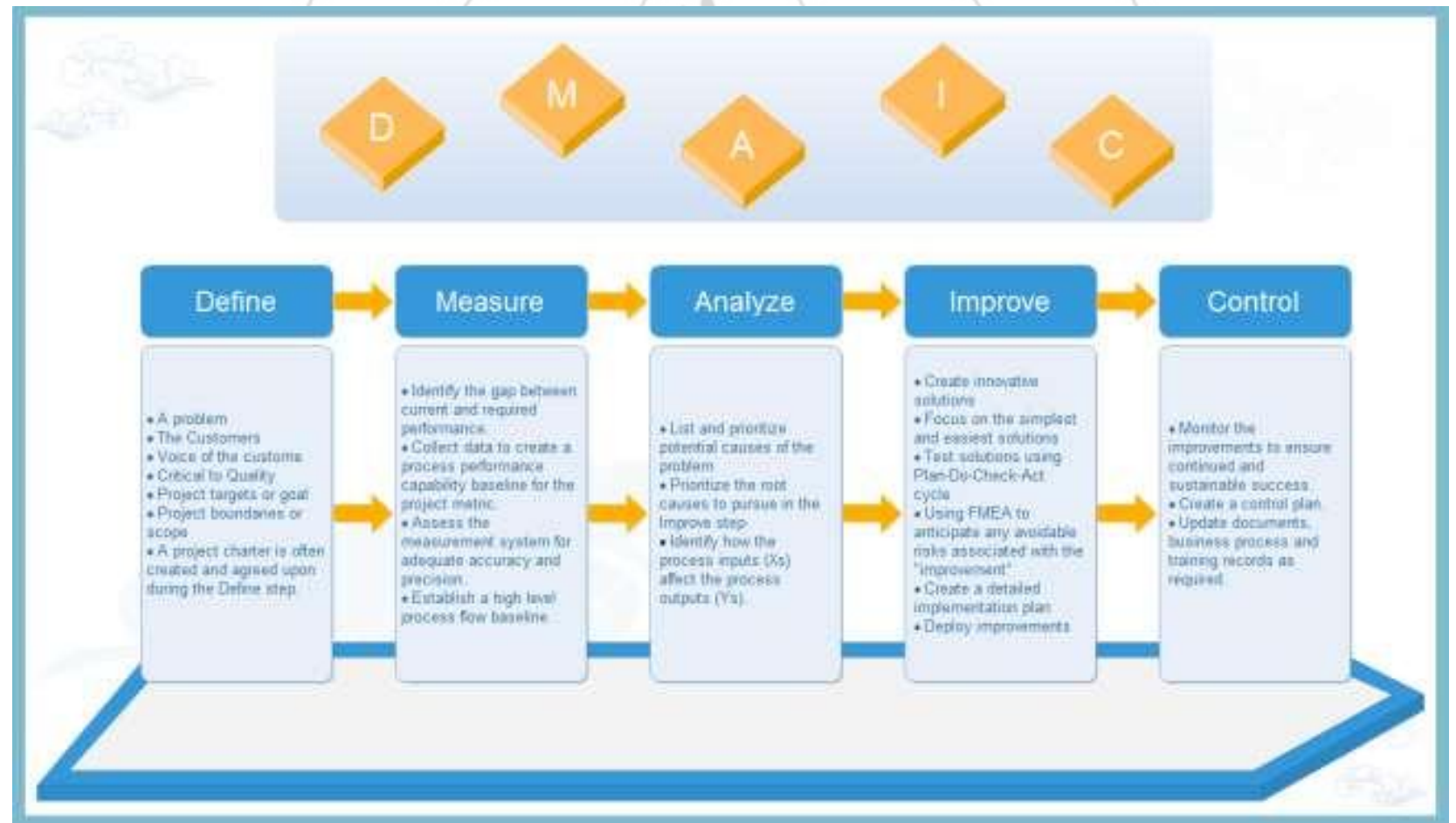

DMAIC (Define, Measure, Analyze, Improve and Control)

\section{Methodology}

DMAIC is an organized task change procedure that enhances your possibility of effectively taking care of an issue. The acronym remains for Define, Measure, Analyze, Improve, and Control.

DMAIC should be used when:

- There is an issue and the main driver is obscure.
- The a lot is on the line and we should be totally certain the arrangement settles the issue.

- A issue exists, arrangements have been attempted, however the underlying driver is still obscure. Each step in the cyclical

DMAIC Process is required to ensure the best possible results. The process steps:

Define the Customer, their Critical to Quality issues, and the Core commerce sequences involved. 


\section{International Journal of Science and Research (IJSR) \\ ISSN (Online): 2319-7064}

Index Copernicus Value (2013): 6.14 | Impact Factor (2015): 6.391

- Define who clients are, what their necessities are for items and administrations, and what their desires are

- Define venture limits $\neg$ the stop and begin of the procedure

- Define the procedure to be enhanced by mapping the procedure stream

Measure the performance of the Core commerce sequences involved.

- Collection of data plan for the process

- Gather data from many sources to decide types of defects and metrics

- Compare results to determine deficit

Analyze the data collected and process map to find root causes of hindrances and opportunities for development.

- Identify holes between current execution and objective execution

- Prioritize chances to make strides

- Identify wellsprings of variety

Improve Enhance the objective procedure by planning innovative answers for fix and avert issues.

- Generate innovate solutions using modern technology and processes

- Expand and deploy completion plan

Control the improvements to keep the process on the latest technology.

- Do not revert back to the "old way"

- Specify the inception, documentation and execution of an ongoing monitoring plan

- Apply the improvements to modify systems and structures (staffing, training, incentives).

Flow chart for DMAIC process:

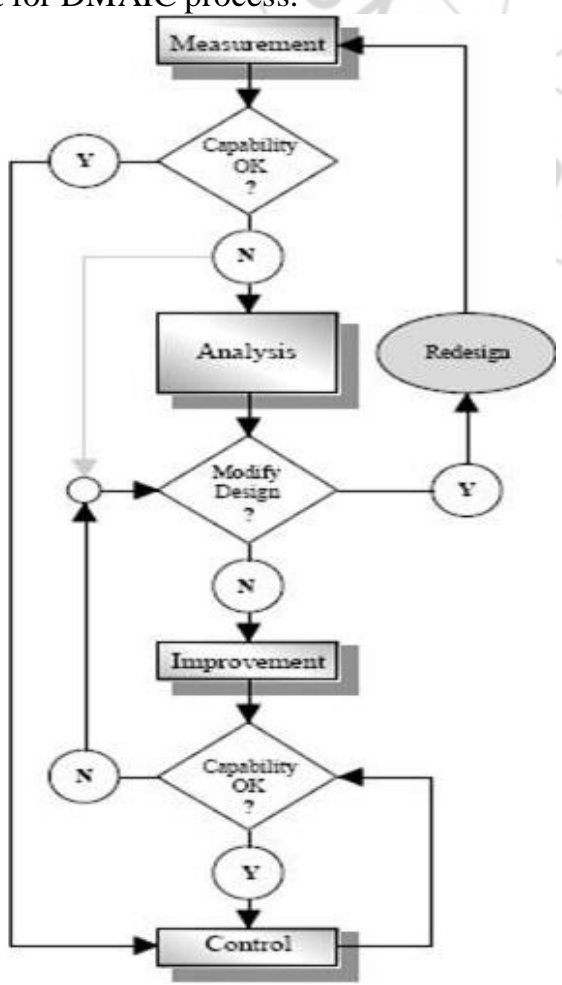

\section{Literature Survey}

Academy sports and Outdoors is one of the leading brand for sports products in USA, having retail stores in more than 50 cities of United States. The brand is well known for its products quality and durability and is the first choice among youths and children. The recent developments in their supply chain strategy requires re-structuring of their transportation and inventory models. Knowing about the company and its DMAIC technology, this project was taken up by me to complete their Analyze and Improve phase.

\section{Problem Definition}

To reduce the cost of transportation from one store to another.

\section{Methodology}

DMAIC methodology was used by the company to cope up with this problem.

\begin{tabular}{|c|c|c|c|}
\hline $\begin{array}{c}\text { Academy } \\
\text { Store }\end{array}$ & $\begin{array}{c}\text { U of H } \\
\text { Store }\end{array}$ & Address & $\begin{array}{c}\text { Cost Per } \\
\text { Mile }\end{array}$ \\
\hline 5 & 1 & 6101 I-20 Fort Worth, Tx 76132 & $\$ 1.52$ \\
\hline 10 & 2 & 1100 W. Arbrook Blvd Arlington, \\
Tx 76015 & $\$ 1.59$ \\
\hline 16 & 3 & $\begin{array}{c}7441 \text { N.E. Loop 820 N. Richland } \\
\text { Hills, Tx 76180 }\end{array}$ & $\$ 1.50$ \\
\hline 17 & 4 & 4045 NC Expwy Plano, Tx 75023 & $\$ 1.61$ \\
\hline 20 & 5 & 8050 Forest Ln Dallas, Tx 75243 & $\$ 1.66$ \\
\hline 21 & 6 & $\begin{array}{r}\text { 3305 Dallas Pkwy, Suite 301 } \\
\text { Plano, Tx 75093 }\end{array}$ & $\$ 1.57$ \\
\hline 37 & 7 & $\begin{array}{r}\text { 3677 Emporium Circle } \\
\text { Mesquite,Tx 75150 }\end{array}$ & $\$ 1.68$ \\
\hline 40 & 8 & $\begin{array}{r}\text { 1523 State Hwy 114 W.Grapevine, } \\
\text { Tx 76051 }\end{array}$ & $\$ 1.57$ \\
\hline 48 & 9 & $\begin{array}{r}\text { 2428 S. Stemmons Fwy } \\
\text { Lewisville,Tx 75067 }\end{array}$ & $\$ 1.56$ \\
\hline
\end{tabular}

Looking at the information given, regression analysis was carried out and the results are shown in the tables below:

\begin{tabular}{|r|c|c|c|c|}
\hline \multicolumn{4}{|c|}{ TRAILER DIMENSIONS PER STORE } & \multirow{2}{*}{ Volume } \\
\cline { 1 - 4 } Store \# & W(") & L(") & H(") & \\
\hline 5 & 100 & 634 & 72 & 4564800 \\
\hline
\end{tabular}

The trailer dimensions were calculated for each of the stores as specified in the cost sheet. The above Fig. shows the volume for the store \#5 
International Journal of Science and Research (IJSR)

ISSN (Online): 2319-7064

Index Copernicus Value (2013): 6.14 | Impact Factor (2015): 6.391

\begin{tabular}{|l|c|c|c|c|c|}
\hline & W(") & L(") & H(") & Volumes & $\begin{array}{c}\text { Total } \\
\text { Volume }\end{array}$ \\
\hline SG TOTE DIMENSIONS & $203 / 4$ & $281 / 8$ & $143 / 4$ & 8608.007813 & \\
\cline { 1 - 4 } FW CART DIMENSIONS & $181 / 2$ & 66 & $723 / 4$ & 88827.75 & 106043.7656 \\
\hline HG TOTE DIMENSIONS & $203 / 4$ & $281 / 8$ & $143 / 4$ & 8608.007813 & \\
\hline
\end{tabular}

The Cartons with SG,FW,HG dimensions were considered independently and their respective volumes were carton with its individual volume and the Total volume calculated. The Fig. above shows the dimensions for each

\begin{tabular}{|c|c|c|c|c|c|c|c|c|c|c|c|c|c|c|}
\hline Store \# & & \multicolumn{2}{|c|}{ SUN 12.15} & \multicolumn{2}{|c|}{ MON 12-16 } & TUE $12-17$ & \multicolumn{2}{|c|}{ WED 12-18 } & \multicolumn{2}{|c|}{ THUR 12-19 } & \multicolumn{2}{|c|}{ FRI 12-20 } & SAT 12-21 & \multirow{2}{*}{\begin{tabular}{|r|r} 
Total \\
55
\end{tabular}} \\
\hline 5 & FW & & 7 & & & 19 & & & \multicolumn{2}{|c|}{10} & \multicolumn{2}{|r|}{19} & & \\
\hline 5 & HG & & 84 & & & 293 & & & & 257 & & 360 & & 994 \\
\hline 5 & \begin{tabular}{|l|l}
56 \\
\end{tabular} & & 26 & & & 62 & & & \multicolumn{2}{|c|}{27} & & 55 & & 170 \\
\hline & & 16 & FW & & 16 & 14 & 26 & 5 & 15 & 2 & 6 & 119 & & \\
\hline & & 16 & HG & & 136 & 499 & 586 & 68 & & 252 & 317 & 2472 & & \\
\hline & & 16 & SG & & 34 & 76 & 42 & 8 & 9 & 19 & 35 & 295 & & \\
\hline & & 17 & FW & & 11 & & 24 & 2 & 21 & 4 & & 60 & & \\
\hline & & 17 & HG & & 301 & & 579 & 36 . & & 210 & & 1455 & & \\
\hline & & 17 & SG & & 56 & & 46 & 5 & 57 & 25 & & 184 & & \\
\hline & & 20 & FW & 16 & & 4 & 10 & & 36 & 3 & 6 & 75 & & \\
\hline & & 20 & HG & 122 & & 348 & 305 & 63 & 34 & 203 & 175 & 1787 & & \\
\hline & & 20 & $\mathrm{SG}$ & 29 & & 42 & 23 & & 83 & 16 & 24 & 217 & & \\
\hline & & 21 & 65 & & 48 & 56 & 19 & & 60 & 49 & 25 & 257 & & \\
\hline & & 21 & FW & & 9 & 23 & 9 & & 17 & 9 & 30 & 97 & & \\
\hline & & 21 & $\mathrm{HG}$ & & 340 & 771 & 189 & 56 & 65 & 562 & 183 & 2610 & & \\
\hline & & 37 & FW & & 17 & 2 & 33 & & 21 & 10 & & 83 & & \\
\hline & & 37 & $\mathrm{HG}$ & & 165 & 201 & 747 & & 677 & 389 & & 1779 & & \\
\hline & & 37 & SG & & 28 & 32 & 74 & & 34 & 35 & & 203 & & \\
\hline & & & 40 & FW & 18 & 22 & 19 & 30 & 7 & 38 & 134 & & & \\
\hline & & & 40 & $\mathrm{HG}$ & 217 & 677 & 407 & 622 & 279 & 328 & 2530 & & & \\
\hline & & & 40 & SG & 33 & 56 & 42 & 93 & 26 & 35 & 285 & & & \\
\hline & & & 48 & FW & 12 & 11 & \begin{tabular}{|l|}
14 \\
\end{tabular} & 38 & 4 & 28 & 107 & & & \\
\hline & & & 48 & $\mathrm{HG}$ & 198 & 558 & 591 & 747 & 292 & 400 & 2786 & & & \\
\hline & & & 48 & $\mathrm{SG}$ & 34 & 51 & 55 & 100 & 24 & 59 & 323 & & & \\
\hline
\end{tabular}

The above tables include the Carton count per division on 7 days of the week for FW,HG and SG

\begin{tabular}{|r|r|r|r|r|r|r|r|r|r|r|}
\hline UH Store no & Academy Store no & Carton FW & Carton HG & Carton SG & Total Demand & Volume of all Cartins & No of trailers & Distance & Cost per mile & Initial Cost \\
\hline 1 & 5 & 52 & 625 & 121 & 798 & 84623112 & 19 & 265.4 & $\$ 1.52$ & $\$ 7,664.75$ \\
\hline 2 & 10 & 62 & 879 & 131 & 1072 & 113679168 & 25 & 345.7 & $\$ 1.59$ & $\$ 13,741.58$ \\
\hline 3 & 16 & 83 & 1186 & 183 & 1452 & 153975888 & 34 & 209.55 & $\$ 1.50$ & $\$ 10,687.05$ \\
\hline 4 & 17 & 61 & 815 & 131 & 1007 & 106786308 & 24 & 268.5 & $\$ 1.61$ & $\$ 10,374.84$ \\
\hline 5 & 20 & 60 & 924 & 132 & 1116 & 118345104 & 26 & 7.1 & $\$ 1.66$ & $\$ 306.44$ \\
\hline 6 & 21 & 175 & 75 & 1207 & 1457 & 154506108 & 34 & 537.8 & $\$ 1.57$ & $\$ 28,707.76$ \\
\hline 7 & 37 & 77 & 960 & 163 & 1200 & 127252800 & 28 & 561.76 & $\$ 1.68$ & $\$ 26,425.19$ \\
\hline 8 & 40 & 71 & 1023 & 160 & 1254 & 132979176 & 30 & 251.4 & $\$ 1.57$ & $\$ 11,840.94$ \\
\hline 9 & 48 & 67 & 1108 & 163 & 1338 & 141886872 & 32 & 266.6 & $\$ 1.56$ & $\$ 13,308.67$ \\
\hline & & & & & & & & Total & $\$ 123,057.22$ \\
\hline
\end{tabular}

*Distances in miles in all the figures

Volume 5 Issue 5, May 2016

www.ijsr.net 


\section{International Journal of Science and Research (IJSR) \\ ISSN (Online): 2319-7064}

Index Copernicus Value (2013): 6.14 | Impact Factor (2015): 6.391

The above table shows the analysis performed for each of the Academy store, the Carton values for FW,HG,SG were calculated (Rounded off to the nearest whole no.). This helped in calculation of Total demand and Volume of Cartons and finally the total cost was calculated.

\section{Results/ Calculations}

The cost per mile sheet highlighted the number of academy stores to be considered. Depending on the same the carton value for FW was calculated by taking into account the carton count per division: Total value of FW for $5,10,16,17,20,21,37,40,48$ was added and divided by 7 . Similar procedure was followed for the Cartons HG, SG respectively.

Total demand $=$ Carton $\mathrm{FW}+$ Carton $\mathrm{HG}+$ Carton SG Volume of 1 full demand equals sum of all total demands Volume of one carton $=$ Volume of 1 full demand $*$ Total demand

Looking at the sheet for trailer dimensions the average trailer volume was calculated.

From the volume of all cartons and one trailer volume. (Number of trailers $=$ Volume of all cartons/one trailer volume)

Similar steps were performed for all the other stores and the store distance in miles with the cost per mile was taken from the distance sheet and cost per mile sheet.

Therefore Initial cost $=$ No of trailers $*$ Distance $*$ Cost per mile

Academy store v/s Total initial cost

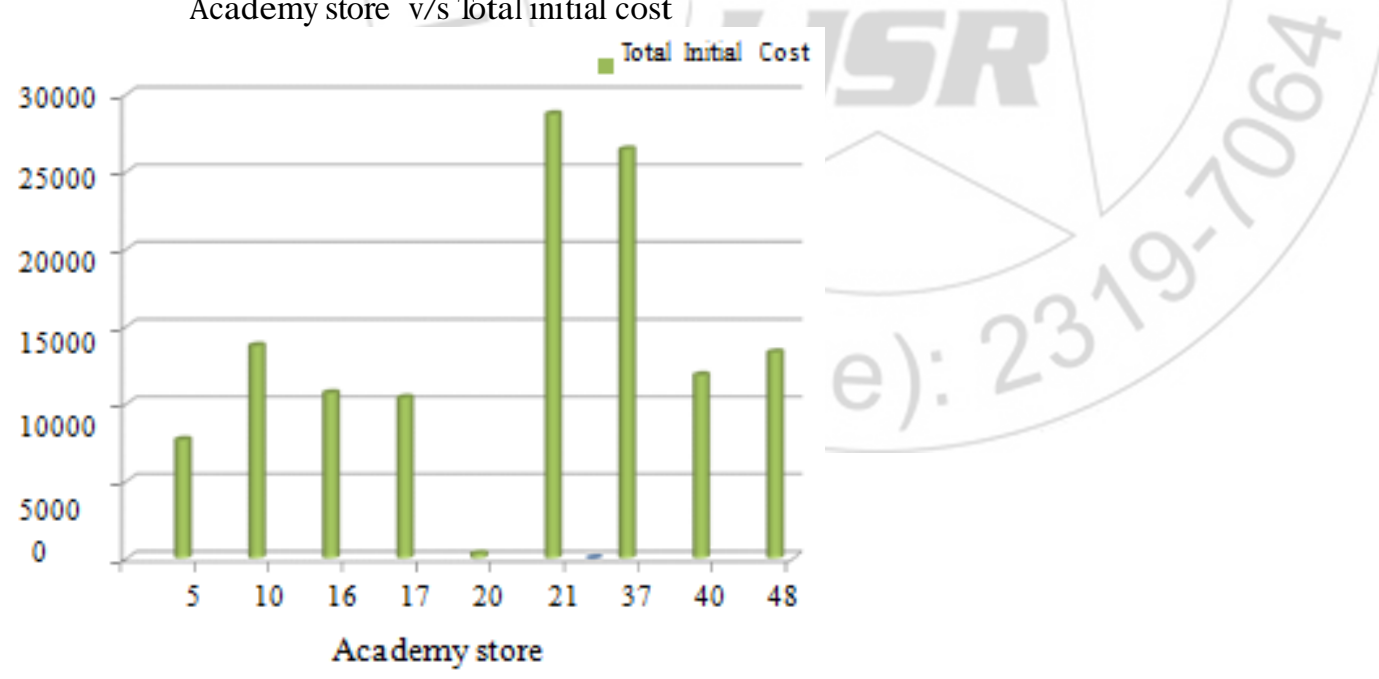

The above Bar graph indicates the relation of Academy store v/s Total initial cost as computed in the above tables.

Results got from the investigation stage for the ideal arrangement had collected the interest.

Further examination was done to enhance the arrangement in order to lessen all out transportation cost and enhance it further. One of the strategies named "Empty Technique" was executed to see the effect on the expense.The strategy fills in as takes after:
1) Decrease the Carton volume SG by half

2) Decreasing the Carton volume of FW by $10 \%$

These two changes starts in acquiring the new volume for the 3 Cartons and further including of them gives the Total New

Volume. With this new volume, the volume for all containers was computed by making utilization of the same system as done beforehand. Therefore: Number of trailers $=$ Volume of all cartons/one trailer volume

Similar steps were performed for all the other stores and the store distance in miles with the cost per mile was taken from the distance sheet and cost per mile sheet.

Hence Initial cost $=$ No of trailers*Distance*Cost per mile as shown in the table below 
International Journal of Science and Research (IJSR)

ISSN (Online): 2319-7064

Index Copernicus Value (2013): 6.14 | Impact Factor (2015): 6.391

\begin{tabular}{|c|c|c|c|c|c|c|c|c|c|c|}
\hline $\begin{array}{l}\text { UH Store } \\
\text { no }\end{array}$ & $\begin{array}{l}\text { Academy } \\
\text { Store no }\end{array}$ & Carton FW & Carton HG & Carton SG & $\begin{array}{l}\text { Total } \\
\text { Demand }\end{array}$ & $\begin{array}{l}\text { Volume of all } \\
\text { Cartons }\end{array}$ & $\begin{array}{l}\text { No of } \\
\text { trailers }\end{array}$ & Distance & $\begin{array}{c}\text { Cost per } \\
\text { mile }\end{array}$ & Initial Cost \\
\hline 1 & 5 & 52 & 625 & 121 & 798 & 74099870.04 & 17 & 265.4 & $\$ 1.52$ & $\$ 6,857.94$ \\
\hline 2 & 10 & 62 & 879 & 131 & 1072 & 99542682.56 & 22 & 345.7 & $\$ 1.59$ & $\$ 12,092.59$ \\
\hline 3 & 16 & 83 & 1186 & 183 & 1452 & 134828335 & 30 & 209.55 & $\$ 1.50$ & $\$ 9,429.75$ \\
\hline 4 & 17 & 61 & 815 & 131 & 1007 & 93506978.86 & 21 & 268.5 & $\$ 1.61$ & $\$ 9,077.99$ \\
\hline 5 & 20 & 60 & 924 & 132 & 1116 & 103628389.7 & 23 & 7.1 & $\$ 1.66$ & $\$ 271.08$ \\
\hline 6 & 21 & 175 & 75 & 1207 & 1457 & 135292619.9 & 30 & 537.8 & $\$ 1.57$ & $\$ 25,330.38$ \\
\hline 7 & 37 & 77 & 960 & 163 & 1200 & 111428376 & 25 & 561.76 & $\$ 1.68$ & $\$ 23,593.92$ \\
\hline 8 & 40 & 71 & 1023 & 160 & 1254 & 116442652.9 & 26 & 251.4 & $\$ 1.57$ & $\$ 10,262.15$ \\
\hline 9 & 48 & 67 & 1108 & 163 & 1338 & 124242639.2 & 29 & 266.6 & $\$ 1.56$ & $\$ 12,060.98$ \\
\hline & & & & & & & & & Total & $\$ 108,976.77$ \\
\hline & & & 16044 & & & & & & & \\
\hline & \multicolumn{2}{|c|}{ Volume of 1 full $d$} & 4564800 & & & & & & & \\
\hline
\end{tabular}

New Volume and Cost table

\section{Conclusion}

\begin{tabular}{|c|c|c|c|c|c|c|c|c|c|c|}
\hline tH Store no & AcademyStone nd & Cartos FW & Carnon HC & Carron SG & Total Demand & Volame of all Cartons & No of trailera & Distance & Cont per mile & Initinl Costr \\
\hline 1 & 5 & 52 & 625 & 121 & 798 & 84623112 & 19 & 265.4 & $\$ 1.52$ & $\$ 7,664,75$ \\
\hline 2 & 10 & 62 & 879 & 131 & 1072 & 113679168 & 25 & 345.7 & $\$ 1.59$ & $\$ 13,741.58$ \\
\hline 3 & 16 & 83 & 1186 & 183 & 1452 & 153975888 & 34 & 209.55 & $\$ 1.50$ & $\$ 10,687.05$ \\
\hline 4 & 17 & 61 & 815 & 131 & 1007 & 106786308 & 24 & 268.5 & $\$ 1.61$ & $\$ 10,374.84$ \\
\hline 5 & 20 & 60 & 924 & 132 & 1116 & 118345104 & 26 & 7.1 & $\$ 1.66$ & $\$ 306.44$ \\
\hline 6 & 21 & 175 & 75 & 1207 & 1457 & 154506108 & 34 & 537.8 & $\$ 1.57$ & $\$ 28,707.76$ \\
\hline 7 & 37 & 77 & 960 & 163 & 1200 & 127252800 & 28 & 561.76 & $\$ 1.68$ & $\$ 26,425.19$ \\
\hline 8 & 40 & 71 & 1023 & 160 & 1254 & 132979176 & 30 & 251.4 & $\$ 1.57$ & $\$ 11,840.94$ \\
\hline 9 & 48 & 67 & 1108 & 163 & 1338 & 141886872 & 32 & 266.6 & $\$ 1.56$ & $\$ 13,308.67$ \\
\hline & & & & & & & & & Total & $\$ 123,057,22$ \\
\hline & & & & & & & & & & \\
\hline & \multicolumn{2}{|c|}{ Volume of 1 full demand } & 106044 & & & & & & & \\
\hline & \multicolumn{2}{|l|}{ one trailer volume } & 4564800 & & & & & & & \\
\hline
\end{tabular}

\begin{tabular}{|c|c|c|c|c|c|c|c|c|c|c|}
\hline $\begin{array}{c}\text { UH Store } \\
\text { no }\end{array}$ & $\begin{array}{l}\text { Academy } \\
\text { Stare no }\end{array}$ & Carton FIV & Carron HC & Cartion SC & $\begin{array}{c}\text { Total } \\
\text { Demand }\end{array}$ & $\begin{array}{c}\text { Volume of all } \\
\text { Carrans }\end{array}$ & $\begin{array}{l}\text { No of } \\
\text { trailers }\end{array}$ & Distance & $\begin{array}{c}\text { Cost per } \\
\text { mile }\end{array}$ & Initial Cost \\
\hline 1 & 5 & 52 & 625 & 121 & 798 & 74099870.04 & 17 & 265.4 & $\$ 1.52$ & $\$ 6,857.94$ \\
\hline 2 & 10 & 62 & 879 & 131 & 1072 & 99542682.56 & 22 & 345.7 & $\$ 1.59$ & $\$ 12,092.59$ \\
\hline 3 & 16 & 83 & 1186 & 183 & 1452 & 134828335 & 30 & 209.55 & $\$ 1.50$ & $\$ 9,429,75$ \\
\hline 4 & 17 & 61 & 815 & 131 & 1007 & 93506978.86 & 21 & 268.5 & $\$ 1.61$ & $\$ 9,077.99$ \\
\hline 5 & 20 & 60 & 924 & 132 & 1116 & 103628389.7 & 23 & 7.1 & $\$ 1.66$ & $\$ 271.08$ \\
\hline 6 & 21 & 175 & 75 & 1207 & 1457 & 135292619.9 & 30 & 537.8 & $\$ 1.57$ & $\$ 25,330.38$ \\
\hline 7 & 37 & 77 & 960 & 163 & 1200 & 111428376 & 25 & 561.76 & $\$ 1.68$ & $\$ 23,593.92$ \\
\hline 8 & 40 & 71 & 1023 & 160 & 1254 & 116442652.9 & 26 & 251.4 & $\$ 1.57$ & $\$ 10,262.15$ \\
\hline \multirow{4}{*}{1} & 48 & 67 & 1108 & 163 & 1338 & 124242639.2 & 29 & 266.6 & $\$ 1.56$ & $\$ 12,060.98$ \\
\hline & & & & & & & & & Total & $\$ 108,976,77$ \\
\hline & & & & & & & & & & \\
\hline & \multicolumn{2}{|c|}{ Volume of 1 full demand } & $1000+4$ & & & New volume & 92850.98 & & & \\
\hline
\end{tabular}

Optimized volume and cost table

On reducing the Carton volumes for SG and FW the initial costs drops down to $\$ 108976.77$ from the initial cost $\$ 123057.22$ (Reduced by $11.5 \%$ ). Highlighted in the tables.
This thus reduced the transportation cost for Academy sports and outdoors. We started with aggregate plan, with that maximized the volume usage. Further the problem was approached with innovative solution and focus was on reducing the air space.

\section{Volume 5 Issue 5, May 2016}




\section{International Journal of Science and Research (IJSR) \\ ISSN (Online): 2319-7064}

Index Copernicus Value (2013): 6.14 | Impact Factor (2015): 6.391

Academy store v/s Total new cost

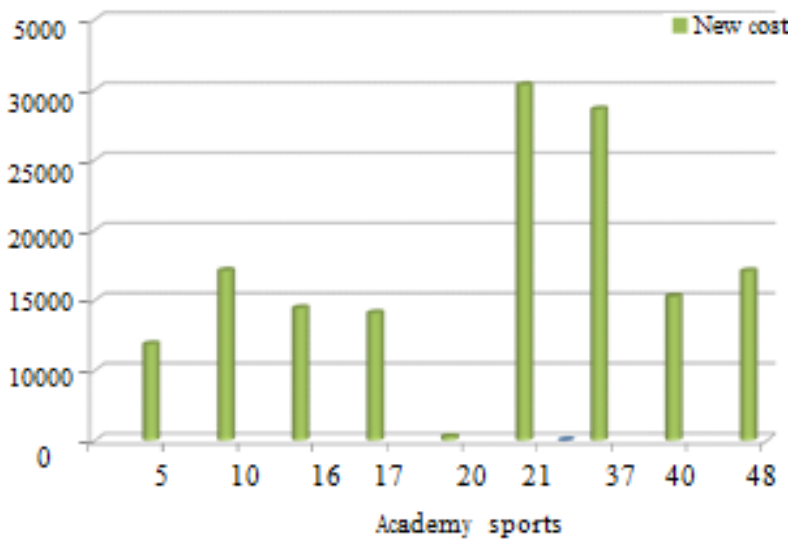

The above Bar graph indicates the relation of Academy store v/s Total new cost as computed in the above table. On going through the observations and studying the tables as shown above, it can be concluded that the total cost was brought down by $11.5 \%$.

DMAIC thus takes a gander at all work as a progression of procedures with characteristic varieties, which can bring about waste or wastefulness. Concentrating on those procedures with most prominent effect on business execution, as characterized by initiative groups, the philosophy includes measurable investigation to evaluate rehashed normal cause varieties - which can then be lessened by the group. DMAIC turns into a nonstop process for quality change and cost decrease streaming all through the organization.

The whole procedure of DMAIC is planned in such a way, to the point that the arrangements won't be provisional in nature and they can be depicted as reasonable arrangements.

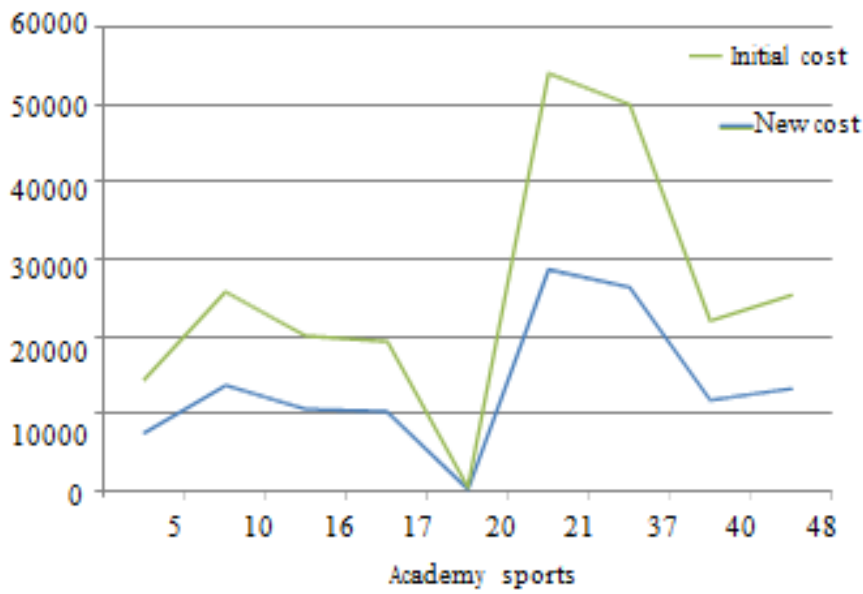

Graph presenting reduction in cost

\section{Future Scope}

It can be said with no uncertainty that DMAIC is a demonstrated technique on the grounds that a decent number of corporate

houses have effectively executed this strategy in a fruitful way. Every one of the angles talked about in the report recommend that DMAIC technique is dependable and to a great degree result arranged too.
There always lies a scope for improvement in any industry and same is the case with Academy sports and outdoors. With effective implementation and utilization of new techniques and cost management processes the cost can further be reduced if some of the constraints are tightened.

\section{References}

[1] http://www.academy.com/

[2] http://asq.org/learn-about-quality/sixsigma/overview/dmaic.html

[3] https://www.isixsigma.com/new-to-sixsigma/dmaic/six-sigma-dmaic-roadmap/

[4] http://www.villanovau.com/resources/six-sigma/sixsigma-methodology-dmaic/\#.Vz9UDZErLIU

[5] http://www.iil.com/emailfiles/downloads/Applyingthe DMAICSteps_Harry\%20Rever.pdf

\section{Author Profile}

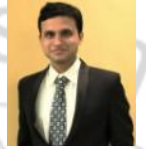

Viraj P. Lele, Post graduate student in Industrial Engineering at University of Houston. Presently pursuing Masters degree with specializations in Supply chain Management, Quality, Operations Research and Manufacturing. 